\title{
Significance of intrinsic breast cancer subtypes on the long-term prognosis after neoadjuvant chemotherapy
}

\author{
Wataru Goto ${ }^{1}$, Shinichiro Kashiwagi ${ }^{1 *}{ }^{10}$, Koji Takada ${ }^{1}$, Yuka Asano ${ }^{1}$, Katsuyuki Takahashi ${ }^{2}$ Hisakazu Fujita ${ }^{3}$, \\ Tsutomu Takashima', Shuhei Tomita², Kosei Hirakawa' and Masaichi Ohira'
}

\begin{abstract}
Background: The prognosis of breast cancer and the treatment response to neoadjuvant chemotherapy (NAC) differ depending on the intrinsic molecular subtypes. We evaluated the prognostic significance of immunohistological subtypes in patients with recurrent breast cancer after treatment with NAC and surgery.

Methods: A total of 237 patients with breast cancer treated with NAC and subsequent curative surgery between 2007 and 2015 were analyzed. The correlation between intrinsic molecular subtypes and clinicopathological features, prognosis, and pathological complete response ( $\mathrm{PCR}$ ) rate of NAC were investigated retrospectively.

Results: There were 55 (23.2\%) patients with recurrence after surgery. No significant difference in post-recurrence survival (PRS) was noted among the subtypes $(p=0.397)$. In patients with estrogen receptor-positive human epidermal growth factor receptor (HER) 2-negative (luminal) malignancy, PRS was significantly better in the pCR group than in the non- $p C R$ group $(p=0.031)$. Conversely, $p C R$ was not a significant predictor of improved PRS in patients with triple-negative breast cancer (TNBC; $p=0.329$ ). Multivariate analysis revealed that the efficacy of NAC [hazard ratio (HR) 300.204, $p<0.001$ ] and the initial metastasis site (HR 15.037, $p=0.005$ ) were independent predictors for PRS in patients with luminal breast cancer, while Ki-67 (HR 51.171, $\mathrm{p}=0.020$ ) and the initial metastasis site (HR 13.318, $p=0.048$ ) were independent predictors for PRS in patients with TNBC.
\end{abstract}

Conclusions: The prognostic factors for each intrinsic subtype should be evaluated separately in patients with recurrent breast cancer following NAC and surgery.

Keywords: Breast cancer, Neoadjuvant chemotherapy, Post-recurrence survival, Intrinsic subtype, Long-term prognosis

\section{Background}

Breast cancer is a heterogeneous disease. Based on gene expression profiling derived from complementary deoxyribonucleic acid (cDNA) microarrays, breast cancer is classified into distinct molecular subtypes, and this diversity is clinically useful in obtaining prognostic information [1].

\footnotetext{
*Correspondence: spqv9ke9@view.ocn.ne.jp

1 Department of Surgical Oncology, Osaka City University Graduate

School of Medicine, 1-4-3 Asahi-machi, Abeno-ku, Osaka 545-8585, Japan

Full list of author information is available at the end of the article
Treatment with neoadjuvant chemotherapy (NAC) increases the rate of breast-conserving surgery and reduces the risk of postoperative recurrence in patients with resectable breast cancer $[2,3]$. In particular, pathological complete response (pCR) after NAC is an independent predictor of favorable outcome in human epidermal growth factor receptor (HER) 2-enriched and triple-negative breast cancer (TNBC) subtypes [4-9].

Although recurrence and metastasis remain the major problems in curative treatment [10], some patients with recurrent breast cancer have a relatively good post-recurrence survival (PRS). PRS is primarily related to tumor biology, including intrinsic subtypes. 
However, few studies have examined the relationship between intrinsic subtypes and the PRS of patients with recurrent breast cancer [11-14]. This study aimed to evaluate the clinicopathological features and PRS according to intrinsic molecular subtypes of breast cancer in patients treated with NAC and subsequent curative surgery. To our knowledge, this study is the first to demonstrate the prognostic significance of immunohistological subtypes in patients with recurrent breast cancer after treatment with NAC and surgery.

\section{Methods}

\section{Patients}

This study included 237 patients with resectable, earlystage breast cancer diagnosed as stage IIA (T1, N1, M0 or T2, N0, and M0), IIB (T2, N1, M0 or T3, N0, and M0), or IIIA (T1-2, N2, M0 or T3, N1-2, and M0) treated with NAC between 2007 and 2015. Tumor stage and T and $\mathrm{N}$ factors were stratified based on the TNM Classification of Malignant Tumors, UICC Seventh Edition [15]. Breast cancer was confirmed histologically via core needle biopsy, or ultrasonography-guided vacuum-assisted biopsy. The tumor stage was determined via systemic imaging studies using computed tomography and bone scintigraphy. Tumors were classified into intrinsic breast cancer subtypes according to the immunohistochemical expression of estrogen receptor (ER), progesterone receptor (PgR), HER-2, and Ki-67. The cut-offs for ER and PgR positivity were both $>0 \%$ positive tumor cells with nuclear staining. Tumors with (1) $3+$ HER2 on immunohistochemical staining, (2) HER2/centromere 17 ratio of $\geq 2.0[16,17]$, and a (3) a Ki-67 labeling index of $\geq 14 \%$ tumor cells on nuclear staining, were considered to exhibit HER2 overexpression [18]. Meanwhile, tumors with a $2+$ HER2 on immunohistochemical staining were analyzed further via fluorescence in situ hybridization.

All patients received a standard NAC protocol consisting of four courses of FEC $100\left(500 \mathrm{mg} / \mathrm{m}^{2}\right.$ fluorouracil, $100 \mathrm{mg} / \mathrm{m}^{2}$ epirubicin, and $500 \mathrm{mg} / \mathrm{m}^{2}$ cyclophosphamide) every 3 weeks, followed by 12 courses of $80 \mathrm{mg} /$ $\mathrm{m}^{2}$ paclitaxel administered weekly [19, 20]. Sixty-four patients had HER2-positive breast cancer and were administered additional [weekly $(2 \mathrm{mg} / \mathrm{kg}$ ) or tri-weekly $(6 \mathrm{mg} / \mathrm{kg})]$ trastuzumab during the paclitaxel treatment [21]. Chemotherapy was administered in the outpatient department. Therapeutic anti-tumor effects were assessed according to the Response Evaluation Criteria in Solid Tumors [22]. pCR was defined as the complete disappearance of the invasive compartment of the lesion with or without intraductal components, including the lymph nodes [2]. Patients underwent mastectomy or breast-conserving surgery after NAC. All patients who underwent breast-conserving surgery also underwent postoperative radiotherapy of the remnant breast. Relapse-free survival (RFS) was defined as the absence of all local, loco-regional, and distant recurrences. Conversely, PRS was defined as the time from tumor relapse to death from any cause. All patients were followed up via physical examination every 3 months, with ultrasonography every 6 months, and computed tomography and bone scintigraphy annually.

\section{Ethics statement}

This study was conducted at Osaka City University Graduate School of Medicine, Osaka, Japan, according to the Reporting Recommendations for Tumor Marker Prognostic Studies guidelines and following a retrospectively written research, pathological evaluation, and statistical plan [23]. The study protocol was approved by the Ethics Committee of Osaka City University. Written informed consent was obtained from all subjects (\#926).

\section{Statistical analyses}

Statistical analyses was performed using the JMP13 software program (SAS Institute, Cary, NC, USA). The associations between intrinsic breast cancer subtypes and clinicopathological variables were evaluated using the $\chi^{2}$ test (or Fisher's exact test when necessary). The KaplanMeier method was used to estimate RFS and PRS. The association between breast cancer subtypes and survival was analyzed via Kaplan-Meier plots and log-rank testing. The Cox proportional hazards model was used to compute univariate and multivariate hazards ratios (HR) for the study parameters with $95 \%$ confidence interval (CI). A p value of $<0.05$ was considered significant.

\section{Results}

\section{Analyses of all breast cancer patients}

The correlation between clinicopathological features and each intrinsic subtype is presented in Table 1. A total of 237 patients were included in this study. Among these, 93 (39.2\%), 21 (8.9\%), 43 (18.1\%), and 80 (33.8\%) had estrogen receptor-positive HER2-negative (luminal), luminal-HER2, HER2-enriched, and TNBC, respectively. Evaluation based on clinicopathological features showed that the pCR rate was significantly higher in patients with HER2-enriched breast cancer and TNBC $(p=0.001)$. The median follow-up period for RFS was 4.2 years (range $0.1-10.0$ years). RFS was not significantly different in each subtype $(\mathrm{p}=0.784, \log$-rank) (Fig. 1a), and it was also significantly longer in patients who achieved $\mathrm{pCR}$ than those who did not $(\mathrm{p}=0.018$, log-rank) (Fig. 1b). In univariate analysis, RFS exhibited a significant relationship with Ki-67 (HR 0.553, 95\% CI 0.325-0.945, $\mathrm{p}=0.031)$ and pathological response (HR 2.046, 95\% CI 1.143-3.891, $\mathrm{p}=0.015)$. Multivariate analysis revealed 
Table 1 Correlation between clinicopathological features and each intrinsic subtype in 237 patients treated with NAC

\begin{tabular}{|c|c|c|c|c|c|}
\hline \multirow[t]{2}{*}{ Parameters } & \multicolumn{4}{|c|}{ Intrinsic subtype } & \multirow[t]{2}{*}{$\mathrm{p}$-value } \\
\hline & $\begin{array}{l}\text { Luminal } \\
(n=93)\end{array}$ & $\begin{array}{l}\text { Luminal-HER2 } \\
(n=21)\end{array}$ & $\begin{array}{l}\text { HER2-enriched } \\
(n=43)\end{array}$ & $\begin{array}{l}\text { TNBC } \\
(n=80)\end{array}$ & \\
\hline \multicolumn{6}{|c|}{ Age at operation } \\
\hline$\leq 56$ & $48(51.6 \%)$ & $12(57.1 \%)$ & $18(41.9 \%)$ & $39(48.8 \%)$ & \\
\hline$>56$ & $45(48.4 \%)$ & $9(42.9 \%)$ & $25(58.1 \%)$ & $41(51.2 \%)$ & 0.641 \\
\hline \multicolumn{6}{|l|}{ Menopause } \\
\hline Pre- & $42(45.1 \%)$ & $9(42.9 \%)$ & $15(34.9 \%)$ & $29(36.3 \%)$ & \\
\hline Post- & $51(54.9 \%)$ & $12(57.1 \%)$ & $28(65.1 \%)$ & $51(63.7 \%)$ & 0.564 \\
\hline \multicolumn{6}{|c|}{ Tumor size (cm) } \\
\hline$\leq 2$ & $13(14.0 \%)$ & $5(23.8 \%)$ & $5(11.6 \%)$ & $9(11.3 \%)$ & \\
\hline$>2$ & $80(86.0 \%)$ & $16(76.2 \%)$ & $38(88.4 \%)$ & 71 (88.7\%) & 0.546 \\
\hline \multicolumn{6}{|c|}{ Lymph node status } \\
\hline Negative & $20(21.5 \%)$ & $9(42.9 \%)$ & $14(32.6 \%)$ & $22(27.5 \%)$ & \\
\hline Positive & $73(78.5 \%)$ & $12(57.1 \%)$ & $29(67.4 \%)$ & $58(72.5 \%)$ & 0.206 \\
\hline \multicolumn{6}{|l|}{ Nuclear grade } \\
\hline 1,2 & $76(81.7 \%)$ & $18(85.7 \%)$ & 35 (81.4\%) & $65(81.3 \%)$ & \\
\hline 3 & $17(18.3 \%)$ & $3(14.3 \%)$ & $8(18.6 \%)$ & $15(18.7 \%)$ & 0.969 \\
\hline \multicolumn{6}{|l|}{ Ki67 (\%) } \\
\hline$\leq 14$ & $34(36.6 \%)$ & $11(52.4 \%)$ & 15 (34.9\%) & $19(23.8 \%)$ & \\
\hline$>14$ & $59(63.4 \%)$ & $10(47.6 \%)$ & $28(65.1 \%)$ & $61(76.2 \%)$ & 0.066 \\
\hline \multicolumn{6}{|c|}{ Pathological response } \\
\hline Non-pCR & $70(73.8 \%)$ & 15 (71.4\%) & $19(44.2 \%)$ & $42(52.5 \%)$ & \\
\hline $\mathrm{pCR}$ & $23(26.2 \%)$ & $6(28.6 \%)$ & $24(55.8 \%)$ & $38(47.5 \%)$ & 0.001 \\
\hline
\end{tabular}

$N A C$ neoadjuvant chemotherapy, HER2 human epidermal growth factor receptor 2, TNBC triple-negative breast cancer, $p C R$ pathological complete response

that Ki-67 (HR 0.548, 95\% CI 0.300-0.991, $\mathrm{p}=0.047)$ and pathological response (HR 1.886, 95\% CI: 1.005-3.803, $\mathrm{p}=0.048)$ were independent prognostic factors for recurrence (Table 2).

Additionally, we investigated the prognostic factors for RFS in each breast cancer subtype. Among the 93 patients with luminal type, no significant difference was observed in RFS according to pathological response $(\mathrm{p}=0.731$, log-rank) (Fig. 1c). In univariate analysis, no clinicopathological feature correlated significantly with RFS. Meanwhile, multivariate analysis revealed that lymph node (HR 4.842, 95\% CI 1.336-31.230, $\mathrm{p}=0.013$ ) and Ki-67 (HR 0.336, 95\% CI 0.119-0.906, $\mathrm{p}=0.031$ ) were independent prognostic factors for recurrence (Table 2). Among the 43 patients with HER2-enriched breast cancer, no significant difference was noted in RFS in relation to pathological response $(\mathrm{p}=0.506, \log$-rank) (Fig. 1d). In univariate and multivariate analyses, there was no independent prognostic factor for recurrence in this study (Table 2). Among the 80 patients with TNBC, RFS was significantly longer in patients who achieved pCR than those who did not $(\mathrm{p}=0.005$, log-rank) (Fig. 1e). In univariate analysis, only pathological response (HR 4.251, 95\% CI $1.557-14.857, \mathrm{p}=0.004$ ) was significantly correlated with RFS. Multivariate analysis also revealed that only pathological response (HR 5.013, 95\% CI 1.612-19.386, $\mathrm{p}=0.004$ ) was an independent prognostic factor for survival. Because the number of patients with luminal-HER2 breast cancer was small $(n=21)$, statistical analyses were not performed (Table 2).

\section{Analyses of patients with recurrence after surgery}

Among the 237 patients, 55 relapsed after surgery. The correlation between clinicopathological features and each intrinsic subtype is presented in Table 3. Among the 55 patients who relapsed, $23(41.8 \%), 3(5.4 \%), 9(16.4 \%)$, and $20(36.4 \%)$ had luminal, luminal-HER2, HER2-enriched, and TNBC, respectively. Evaluation based on clinicopathological features revealed that there was no significant correlation between each intrinsic subtype and any clinicopathological parameter, including $\mathrm{pCR}(\mathrm{p}=0.306)$. The median follow-up period for PRS was 1.5 years (range 0.1-7.9 years). Although PRS was the worst in patients with TNBC, it was not significantly different in each subtype ( $\mathrm{p}=0.397$, log-rank) (Fig. 2a). PRS was also significantly longer in patients who achieved pCR than those who did not ( $p=0.021$, log-rank) (Fig. $2 b$ ). In univariate analysis, PRS exhibited a significant relationship 
a

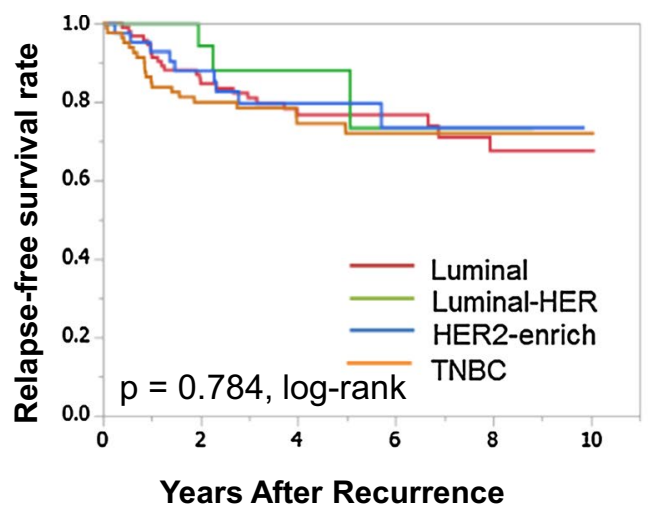

C
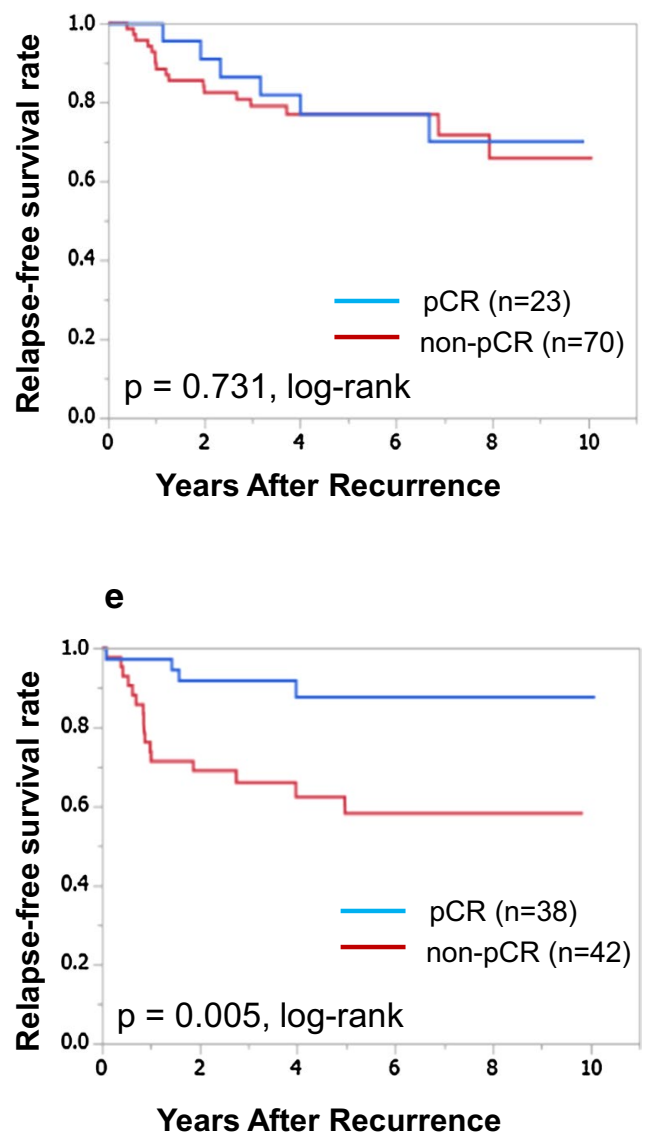

b

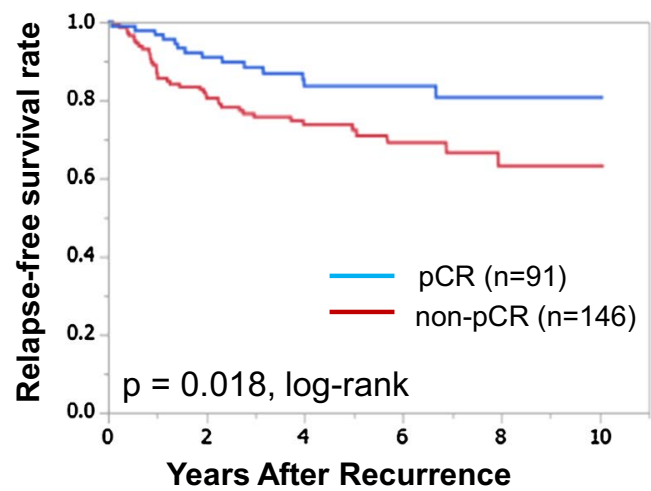

d

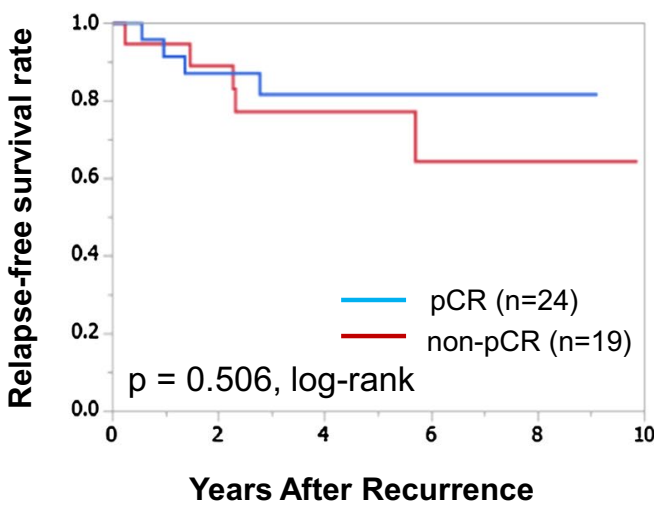

Fig. 1 Relapse-free survival (RFS) for each intrinsic subtype and for pathological response. RFS was not significantly different in each subtype $(p=0.784$, log-rank) (a). Patients who achieved pCR had significantly better RFS among all breast cancers ( $p=0.018$, log-rank) (b). RFS was not significantly differ between patients with $p C R$ and non-pCR of Luminal breast cancer ( $p=0.731$, log-rank) (c). of HER2-enriched breast cancer $(p=0.506$, log-rank) (d). Patients who achieved $p C R$ had significantly better RFS of TNBC ( $p=0.005$, log-rank) (e) 
Table 2 Univariate and multivariate analyses with respect to relapse-free survival in breast cancer subtypes

\begin{tabular}{|c|c|c|c|c|c|c|}
\hline & \multicolumn{3}{|c|}{ Univariate analysis } & \multicolumn{3}{|c|}{ Multivariate analysis } \\
\hline & Hazard ratio & $95 \% \mathrm{Cl}$ & p-value & Hazard ratio & $95 \% \mathrm{Cl}$ & p-value \\
\hline \multicolumn{7}{|l|}{ All breast cancer $(n=237)$} \\
\hline Age $(\leq 56)$ & 1.491 & $0.877-2.565$ & 0.141 & 2.130 & $0.828-4.847$ & 0.111 \\
\hline Menopause (-) & 1.220 & $0.709-2.074$ & 0.467 & 0.703 & $0.310-1.802$ & 0.439 \\
\hline Tumor size (>2) & 1.679 & $0.738-4.830$ & 0.236 & 1.509 & $0.640-4.436$ & 0.372 \\
\hline Lymph node $(+)$ & 1.720 & $0.904-3.620$ & 0.102 & 1.829 & $0.950-3.880$ & 0.072 \\
\hline Nuclear grade (3) & 0.899 & $0.427-1.713$ & 0.758 & 1.452 & $0.642-3.064$ & 0.356 \\
\hline Ki67 (> 14) & 0.553 & $0.325-0.945$ & 0.031 & 0.548 & $0.300-0.991$ & 0.047 \\
\hline Pathological response (non-pCR) & 2.046 & $1.143-3.891$ & 0.015 & 1.886 & $1.005-3.746$ & 0.048 \\
\hline \multicolumn{7}{|l|}{ Luminal $(n=93)$} \\
\hline Age $(\leq 56)$ & 1.223 & $0.537-2.871$ & 0.631 & 5.007 & $0.988-20.715$ & 0.052 \\
\hline Menopause (-) & 0.864 & $0.367-1.974$ & 0.730 & 0.268 & $0.072-1.290$ & 0.094 \\
\hline Tumor size $(>2)$ & 2.077 & $0.607-13.00$ & 0.276 & 2.444 & $0.650-16.093$ & 0.206 \\
\hline Lymph node $(+)$ & 3.188 & $0.935-19.94$ & 0.066 & 4.842 & $1.336-31.230$ & 0.013 \\
\hline Nuclear grade (3) & 1.110 & $0.365-2.799$ & 0.839 & 2.386 & $0.640-8.278$ & 0.187 \\
\hline Ki67 (> 14) & 0.587 & $0.256-1.360$ & 0.209 & 0.336 & $0.119-0.906$ & 0.031 \\
\hline Pathological response (non-pCR) & 1.178 & $0.487-3.281$ & 0.728 & 1.403 & $0.513-4.387$ & 0.523 \\
\hline \multicolumn{7}{|l|}{ HER2-enriched $(n=43)$} \\
\hline Age $(\leq 56)$ & 2.124 & $0.559-8.614$ & 0.262 & 1.059 & $0.050-9.029$ & 0.962 \\
\hline Menopause (-) & 1.877 & $0.463-7.126$ & 0.359 & 6.241 & $0.451-175.683$ & 0.177 \\
\hline Tumor size $(>2)$ & 1.063 & $0.195-19.750$ & 0.953 & 0.281 & $0.024-6.713$ & 0.368 \\
\hline Lymph node $(+)$ & 1.859 & $0.447-12.523$ & 0.417 & 1.683 & $0.292-15.232$ & 0.579 \\
\hline Nuclear grade (3) & 0.405 & $0.022-2.245$ & 0.344 & 0.163 & $0.007-1.387$ & 0.103 \\
\hline Ki67 (> 14) & 0.607 & $0.160-2.460$ & 0.464 & 0.868 & $0.140-6.349$ & 0.882 \\
\hline Pathological response (non-pCR) & 1.556 & $0.412-6.289$ & 0.508 & 4.430 & $0.569-55.264$ & 0.163 \\
\hline \multicolumn{7}{|l|}{ TNBC $(n=80)$} \\
\hline Age $(\leq 56)$ & 1.483 & $0.611-3.697$ & 0.381 & 2.697 & $0.542-10.890$ & 0.205 \\
\hline Menopause (-) & 1.318 & $0.515-3.195$ & 0.550 & 0.539 & $0.136-2.660$ & 0.416 \\
\hline Tumor size (>2) & 1.155 & $0.333-7.263$ & 0.844 & 0.643 & $0.160-4.296$ & 0.596 \\
\hline Lymph node $(+)$ & 1.065 & $0.411-3.282$ & 0.904 & 0.625 & $0.214-2.083$ & 0.421 \\
\hline Nuclear grade (3) & 1.098 & $0.314-2.999$ & 0.868 & 2.909 & $0.679-11.523$ & 0.143 \\
\hline Ki67 (> 14) & 0.488 & $0.202-1.250$ & 0.130 & 0.486 & $0.150-1.518$ & 0.213 \\
\hline Pathological response (non-pCR) & 4.251 & $1.557-14.857$ & 0.004 & 5.013 & $1.612-19.386$ & 0.004 \\
\hline
\end{tabular}

Values in parentheses are $95 \%$ confidence intervals

$C l$ confidence interval, $p C R$ pathological complete response, $T N B C$ triple-negative breast cancer

with pathological response (HR 3.321, 95\% CI 1.26411.437, $\mathrm{p}=0.013$ ) and RFS (HR 2.439, 95\% CI 1.0057.269, $\mathrm{p}=0.049$ ). Multivariate analysis showed that tumor size (HR 5.533, 95\% CI 1.251-39.287, $\mathrm{p}=0.023$ ), Ki-67 (HR 2.606, 95\% CI 1.028-6.780, p=0.044), pathological response (HR 4.355, 95\% CI 1.438-16.871, $\mathrm{p}=0.008$ ), and metastatic site (HR 2.496, 95\% CI 1.0076.126, $\mathrm{p}=0.048)$ had strong prognostic significance for PRS (Table 4).

Among the 23 patients with luminal type, PRS was significantly longer in patients who achieved pCR than those who did not ( $p=0.031$, log-rank) (Fig. 2c). Pathological response (HR 7.144, 95\% CI 1.358-131.592, $\mathrm{p}=0.016$ ) was significantly correlated with PRS in univariate analysis. Multivariate analysis revealed that tumor size (HR $3.108 \times 10^{9}, 95 \%$ CI $\left.1.662-7.5 \times 10^{179}, \mathrm{p}=0.024\right)$, lymph node (HR $1.772 \times 10^{10}$, 95\% CI 1.806-unparsable, $\mathrm{p}=0.028$ ), pathological response (HR 300.204, 95\% CI 7.824-52,372.311, $\mathrm{p}<0.001)$, and metastatic site (HR 15.037, 95\% CI 2.182-159.623, $\mathrm{p}=0.005)$ were independent prognostic factors for survival (Table 4). Among the 20 patients with TNBC, there was no significant difference in PRS in relation to pathological response $(\mathrm{p}=0.329$, log-rank) (Fig. $2 \mathrm{~d}$ ). In univariate analysis, only 
Table 3 Correlation between clinicopathological features and each intrinsic subtype in $\mathbf{5 5}$ patients with recurrence after surgery

\begin{tabular}{|c|c|c|c|c|c|}
\hline \multirow[t]{2}{*}{ Parameters } & \multicolumn{4}{|c|}{ Intrinsic subtype } & \multirow[t]{2}{*}{$p$-value } \\
\hline & $\begin{array}{l}\text { Luminal } \\
(n=23)\end{array}$ & $\begin{array}{l}\text { Luminal-HER2 } \\
(n=3)\end{array}$ & $\begin{array}{l}\text { HER2-enriched } \\
(n=9)\end{array}$ & $\begin{array}{l}\text { TNBC } \\
(n=20)\end{array}$ & \\
\hline \multicolumn{6}{|c|}{ Age at operation } \\
\hline$\leq 56$ & $13(56.5 \%)$ & $2(66.7 \%)$ & $5(55.6 \%)$ & $11(55.0 \%)$ & \\
\hline$>56$ & $10(43.5 \%)$ & $1(33.3 \%)$ & $4(44.4 \%)$ & $9(45.0 \%)$ & 0.985 \\
\hline \multicolumn{6}{|l|}{ Menopause } \\
\hline Pre- & $10(43.5 \%)$ & $2(66.7 \%)$ & $4(44.4 \%)$ & $8(40.0 \%)$ & \\
\hline Post- & $13(56.5 \%)$ & $1(33.3 \%)$ & $5(55.6 \%)$ & $12(60.0 \%)$ & 0.860 \\
\hline \multicolumn{6}{|c|}{ Tumor size (cm) } \\
\hline$\leq 2$ & $2(8.7 \%)$ & $0(0.0 \%)$ & $1(11.1 \%)$ & $2(10.0 \%)$ & \\
\hline$>2$ & $21(91.3 \%)$ & $3(100.0 \%)$ & $8(88.9 \%)$ & $18(90.0 \%)$ & 0.888 \\
\hline \multicolumn{6}{|c|}{ Lymph node status } \\
\hline Negative & $2(8.7 \%)$ & $1(33.3 \%)$ & $2(22.2 \%)$ & $5(25.0 \%)$ & \\
\hline Positive & $21(91.3 \%)$ & $2(66.7 \%)$ & $7(77.8 \%)$ & $15(75.0 \%)$ & 0.437 \\
\hline \multicolumn{6}{|l|}{ Nuclear grade } \\
\hline 1,2 & $18(78.3 \%)$ & $3(100.0 \%)$ & $8(88.9 \%)$ & $16(80.0 \%)$ & \\
\hline 3 & $5(21.7 \%)$ & $0(0.0 \%)$ & $1(11.1 \%)$ & $4(20.0 \%)$ & 0.620 \\
\hline \multicolumn{6}{|l|}{ Ki67 (\%) } \\
\hline$\leq 14$ & $11(47.8 \%)$ & $3(100.0 \%)$ & $4(44.4 \%)$ & $8(40.0 \%)$ & \\
\hline$>14$ & $12(52.2 \%)$ & $0(0.0 \%)$ & $5(55.6 \%)$ & $12(60.0 \%)$ & 0.175 \\
\hline \multicolumn{6}{|c|}{ Pathological response } \\
\hline Non-pCR & $17(73.9 \%)$ & $3(100.0 \%)$ & $5(55.6 \%)$ & $16(80.0 \%)$ & \\
\hline $\mathrm{pCR}$ & $6(26.1 \%)$ & $0(0.0 \%)$ & $4(44.4 \%)$ & $4(20.0 \%)$ & 0.306 \\
\hline \multicolumn{6}{|l|}{ Metastatic site } \\
\hline Local/bone & $16(69.6 \%)$ & $2(66.7 \%)$ & $5(55.6 \%)$ & $12(60.0 \%)$ & \\
\hline Distant & 7 (30.4\%) & $1(33.3 \%)$ & $4(44.4 \%)$ & $8(40.0 \%)$ & 0.866 \\
\hline \multicolumn{6}{|c|}{ Relapse-free survival (years) } \\
\hline$<2$ & $13(56.5 \%)$ & $1(33.3 \%)$ & $5(55.6 \%)$ & $16(80.0 \%)$ & \\
\hline$\geq 2$ & $10(43.5 \%)$ & $2(66.7 \%)$ & $4(44.4 \%)$ & $4(20.0 \%)$ & 0.220 \\
\hline
\end{tabular}

HER2 human epidermal growth factor receptor 2, TNBC triple-negative breast cancer, $p C R$ pathological complete response

Ki-67 (HR 4.242, 95\% CI 1.078-28.056, $\mathrm{p}=0.038$ ) was significantly correlated with PRS. Multivariate analysis revealed that Ki-67 (HR 51.171, 95\% CI 1.769-4346.194, $\mathrm{p}=0.020)$ and metastatic site (HR 13.318, 95\% CI 1.021$540.473, \mathrm{p}=0.048$ ) were independent prognostic factors for survival. Because the number of patients with luminal-HER2 $(\mathrm{n}=3)$ and HER2-enriched $(\mathrm{n}=9)$ breast cancer was small, statistical analyses were not performed (Table 4).

\section{Discussion}

Classification of breast cancer intrinsic subtypes is useful in the prediction of therapeutic response and prognosis, mainly for the primary tumor. However, there have been few studies that stratify patients with recurrent breast cancer by intrinsic subtype [11-14]. These studies reported that ER-negative breast cancer or TNBC was significantly associated with poor prognosis. However, these investigations were not examined by each intrinsic subtype of breast cancer. In our study, among 20 TNBC patients with recurrence, low Ki-67 and metastatic site (local or bone) were significantly associated with good prognosis. In addition, although these studies included patients who were not treated with NAC, NAC is the gold standard of care for breast cancer. Our study is the first to investigate the prognostic factor of recurrent breast cancer after treatment with NAC and surgery in all intrinsic subtypes.

In the present study, patients with HER2-enriched breast cancer and TNBC had significantly higher pCR rates among all the patient groups. In particular, RFS after NAC and surgery was significantly longer for patients with TNBC who achieved pCR. Because some 
a

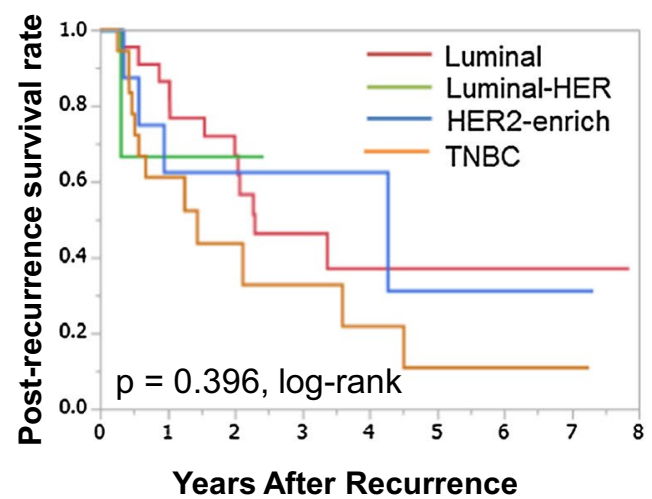

C

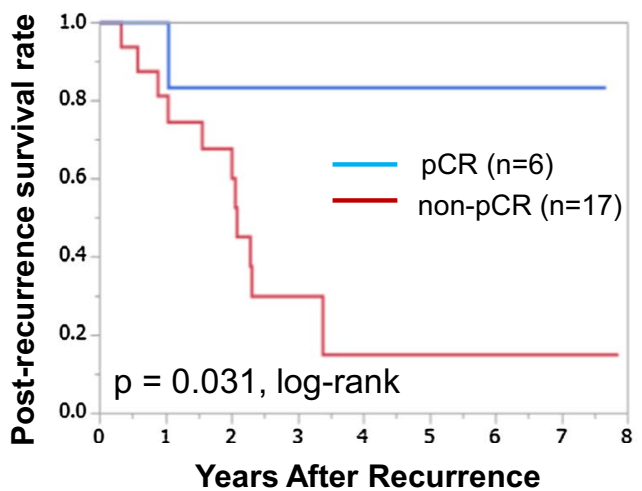

b

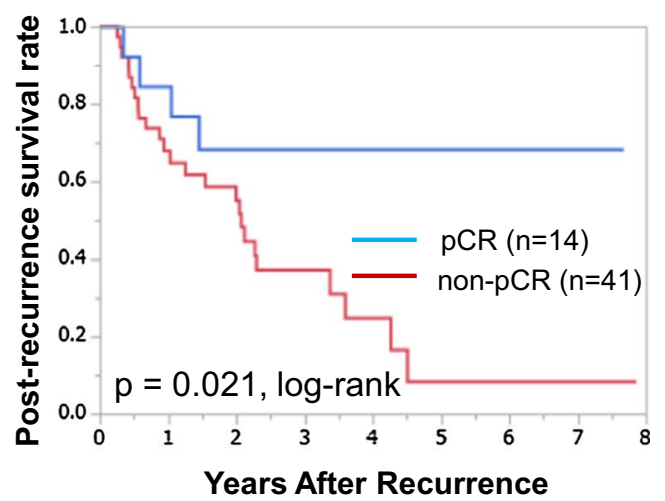

d

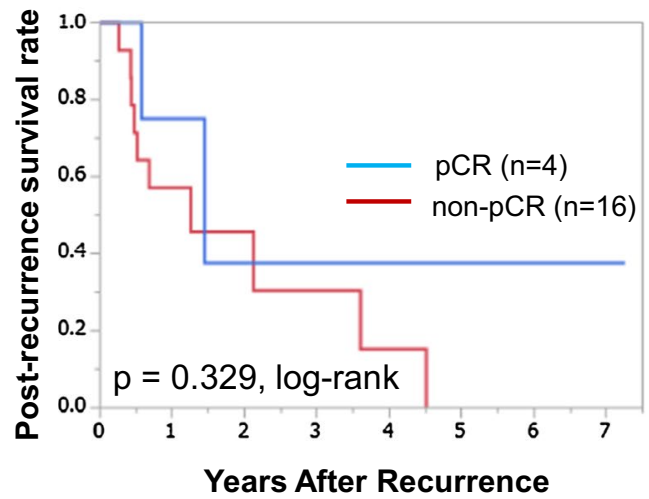

Fig. 2 Post-recurrence survival (PRS) for each intrinsic subtype and for pathological response. Although TNBC was associated with the worst prognosis, PRS was not significantly different in each subtype ( $p=0.396$, log-rank) (a). Patients who achieved $p C R$ had significantly better PRS among all breast cancers ( $p=0.021$, log-rank) (b). Patients who achieved $p C R$ had significantly better PRS of Luminal breast cancer ( $p=0.031$, log-rank) (c). PRS was not significantly differ between patients with $p C R$ and non-pCR of TNBC ( $p=0.329$, log-rank) (d)

previous studies suggested that the treatment response of highly malignant breast cancers, namely, HER2-enriched breast cancer and TNBC, is related to the number of tumor-infiltrating lymphocytes, both are considered to have high immunoactivity [24-27]. However, among patients who relapsed after surgery, no association between each subtype and clinicopathological features was found, including pathological response. Additionally, PRS was significantly better for patients with luminal breast cancer who achieved pCR, but not for those with TNBC. Luminal breast cancer comprises epithelial cells and has low invasion capability, whereas TNBC comprises mesenchymal cells, and has high invasion and migration capabilities $[28,29]$. Compared to that of the primary tumor, relapsed breast cancer after NAC and surgery often acquires resistance to chemotherapy; thus, the prognosis may depend on the degree of invasion or migration rather than immunoactivity.
In terms of metastatic sites at relapse, distant metastasis, such as the liver or lung, excluding bone, is considered life-threatening and is often treated with chemotherapy based on the first-line regimen [30]. Even in our study, the metastatic site was an independent prognostic factor for both the luminal and TNBC subtypes. A recent study reported that disease-free interval was significantly associated with PRS, particularly in luminal breast cancer [31]. However, in this study, there was no relationship between RFS and PRS for both luminal breast cancer and TNBC. The reason for this inconsistent result may be that we only analyzed patients treated with NAC. Future studies may find that cyclin-dependent kinase 4/6 inhibitors (palbociclib, ribociclib, and abemaciclib) could be an effective treatment modality for cases of recurrent luminal cancer that did not achieve pCR.

In the present study, patients were classified into subtypes according to findings from core needle biopsy 
Table 4 Univariate and multivariate analyses with respect to post-recurrence survival in breast cancer subtypes

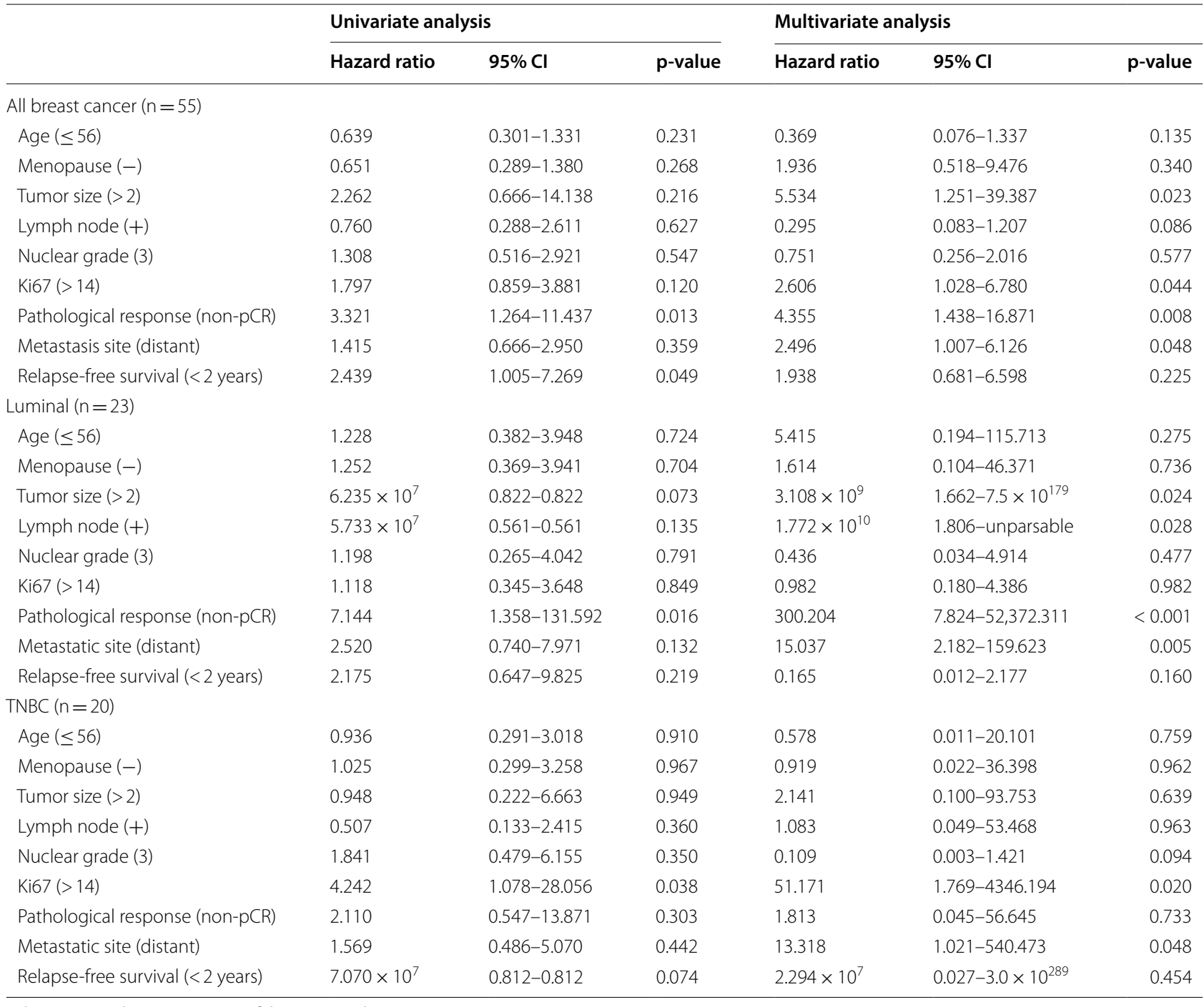

Values in parentheses are $95 \%$ confidence intervals

$C l$ confidence interval, $p C R$ pathological complete response, $T N B C$ triple-negative breast cancer

before NAC, while it has been reported that the receptor status of the relapsed breast cancer after NAC may change [32, 33]. Re-biopsy after recurrence is recommended because it may improve information for creating an individualized treatment plan [16]. However, re-biopsy of distant recurrence is often difficult, including the brain or bone, and we did not analyze it in this study. Instead of core needle biopsy of the tumor, liquid biopsy, such as of circulating tumor cells, cell-free DNA, and tumor-derived exosomes, is likely to influence the treatment strategy in the future [34,35].

A potential limitation of the current study is that we did not evaluate luminal-HER2, and HER2-enriched breast cancer in detail because of the small sample size of our study. Further prospective cohort studies are therefore needed to address these limitations.

\section{Conclusions}

This study is the first to investigate the PRS of patients treated with NAC and subsequent curative surgery in each intrinsic molecular subtype. It is important to separately evaluate the prognostic factors for each intrinsic subtype in patients with recurrent breast cancer following NAC and surgery.

\section{Abbreviations}

NAC: neoadjuvant chemotherapy; pCR: pathological complete response; PRS: post-recurrence survival; HER: human epidermal growth factor receptor; TNBC: 
triple-negative breast cancer; HR: hazard ratio; ER: estrogen receptor; PgR: progesterone receptor; RFS: relapse-free survival; Cl: confidence interval.

\section{Authors' contributions}

All authors were involved in the preparation of this manuscript. WG collected the data, and wrote the manuscript. SK, KTakada, YA, KTakahashi and TT performed the operation and designed the study. WG, SK and ST summarized the data and revised the manuscript. $\mathrm{HF}, \mathrm{KH}$ and $\mathrm{MO}$ substantial contribution to the study design, performed the operation, and revised the manuscript. All authors read and approved the final manuscript.

\section{Author details}

${ }^{1}$ Department of Surgical Oncology, Osaka City University Graduate School of Medicine, 1-4-3 Asahi-machi, Abeno-ku, Osaka 545-8585, Japan. ${ }^{2}$ Department of Pharmacology, Osaka City University Graduate School of Medicine, 1-4-3 Asahi-machi, Abeno-ku, Osaka 545-8585, Japan. ${ }^{3}$ Department of Scientific and Linguistic Fundamentals of Nursing, Osaka City University Graduate School of Nursing, 1-5-17 Asahi-machi, Abeno-ku, Osaka 545-0051, Japan.

\section{Acknowledgements}

We thank Wakaba Fukushima (Department of Public Health, Osaka City University Graduate School of Medicine) for helpful advice regarding statistical analysis. And, we thank Yayoi Matsukiyo and Tomomi Okawa (Department of Surgical Oncology, Osaka City University Graduate School of Medicine) for helpful advice regarding data management.

\section{Competing interests}

The authors declare that they have no competing interests.

\section{Availability of data and materials}

The datasets supporting the conclusions of this article is included within the article.

\section{Consent for publication}

Written informed consent was obtained from all patients.

\section{Ethics approval and consent to participate}

Written informed consent was obtained from all subjects. This research conformed to the provisions of the Declaration of Helsinki in 2013. All patients were informed of the investigational nature of this study and provided their written, informed consent. The study protocol was approved by the Ethics Committee of Osaka City University (\#926).

\section{Funding}

This study was funded by grants from the Japan Society for the Promotion of Science (KAKENHI, Nos. 25461992, 26461957, and 17K10559) to Shinichiro Kashiwagi.

\section{Publisher's Note}

Springer Nature remains neutral with regard to jurisdictional claims in published maps and institutional affiliations.

Received: 10 May 2018 Accepted: 6 November 2018 Published online: 09 November 2018

\section{References}

1. Sorlie T, Perou CM, Tibshirani R, Aas T, Geisler S, Johnsen H, Hastie T, Eisen $M B$, van de Rijn M, Jeffrey SS, et al. Gene expression patterns of breast carcinomas distinguish tumor subclasses with clinical implications. Proc Natl Acad Sci USA. 2001;98:10869-74.

2. Wolmark N, Wang J, Mamounas E, Bryant J, Fisher B. Preoperative chemotherapy in patients with operable breast cancer: nine-year results from National Surgical Adjuvant Breast and Bowel Project B-18. J Natl Cancer Inst Monogr. 2001;2001:96-102.

3. van der Hage JA, van de Velde CJ, Julien JP, Tubiana-Hulin M, Vandervelden C, Duchateau L. Preoperative chemotherapy in primary operable breast cancer: results from the European Organization for Research and Treatment of Cancer trial 10902. J Clin Oncol. 2001;19:4224-37.
4. Bear HD, Anderson S, Smith RE, Geyer CE Jr, Mamounas EP, Fisher B, Brown AM, Robidoux A, Margolese R, Kahlenberg MS, et al. Sequential preoperative or postoperative docetaxel added to preoperative doxorubicin plus cyclophosphamide for operable breast cancer: National Surgical Adjuvant Breast and Bowel Project Protocol B-27. J Clin Oncol. 2006;24:2019-27.

5. Rastogi P, Anderson SJ, Bear HD, Geyer CE, Kahlenberg MS, Robidoux A, Margolese RG, Hoehn JL, Vogel VG, Dakhil SR, et al. Preoperative chemotherapy: updates of National Surgical Adjuvant Breast and Bowel Project Protocols B-18 and B-27. J Clin Oncol. 2008;26:778-85.

6. Bhargava R, Beriwal S, Dabbs DJ, Ozbek U, Soran A, Johnson RR, Brufsky AM, Lembersky BC, Ahrendt GM. Immunohistochemical surrogate markers of breast cancer molecular classes predicts response to neoadjuvant chemotherapy: a single institutional experience with 359 cases. Cancer. 2010;116:1431-9.

7. Kaufmann M, von Minckwitz G, Mamounas EP, Cameron D, Carey LA, Cristofanilli M, Denkert C, Eiermann W, Gnant M, Harris JR, et al. Recommendations from an international consensus conference on the current status and future of neoadjuvant systemic therapy in primary breast cancer. Ann Surg Oncol. 2012;19:1508-16.

8. Kuroi K, Toi M, Ohno S, Nakamura S, Iwata H, Masuda N, Sato N, Tsuda H, Kurosumi M, Akiyama F. Prognostic significance of subtype and pathologic response in operable breast cancer; a pooled analysis of prospective neoadjuvant studies of JBCRG. Breast Cancer. 2015;22:486-95.

9. Bonnefoi H, Litiere S, Piccart M, MacGrogan G, Fumoleau P, Brain E, Petit T, Rouanet P, Jassem J, Moldovan C, et al. Pathological complete response after neoadjuvant chemotherapy is an independent predictive factor irrespective of simplified breast cancer intrinsic subtypes: a landmark and two-step approach analyses from the EORTC 10994/BIG 1-00 phase III trial. Ann Oncol. 2014;25:1128-36.

10. Carlson RW, Allred DC, Anderson BO, Burstein HJ, Edge SB, Farrar WB, Forero A, Giordano SH, Goldstein LJ, Gradishar WJ, et al. Metastatic breast cancer, version 1.2012: featured updates to the NCCN guidelines. J Natl Compr Cancer Netw. 2012;10:821-9.

11. Kobayashi K, Ito Y, Matsuura M, Fukada I, Horii R, Takahashi S, Akiyama F, Iwase T, Hozumi Y, Yasuda Y, Hatake K. Impact of immunohistological subtypes on the long-term prognosis of patients with metastatic breast cancer. Surg Today. 2016:46:821-6.

12. Sanchez C, Camus M, Medina L, Oddo D, Artigas RC, Perez Sepulveda A Dominguez F, Razmilic D, Navarro MR, Galindo H, Acevedo F. Clinicopathologic subtypes of breast cancer primary tumors are related to prognosis after recurrence. Asian Pac J Cancer Prev. 2016;17:5081-6.

13. Kimbung S, Kovacs A, Danielsson A, Bendahl PO, Lovgren K, Frostvik Stolt M, Tobin NP, Lindstrom L, Bergh J, Einbeigi Z, et al. Contrasting breast cancer molecular subtypes across serial tumor progression stages: biological and prognostic implications. Oncotarget. 2015;6:33306-18.

14. Wu X, Baig A, Kasymjanova G, Kafi K, Holcroft C, Mekouar H, Carbonneau A, Bahoric B, Sultanem K, Muanza T. Pattern of local recurrence and distant metastasis in breast cancer by molecular subtype. Cureus. 2016:8:e924.

15. Greene FL, Sobin LH. A worldwide approach to the TNM staging system: collaborative efforts of the AJCC and UICC. J Surg Oncol. 2009:99:269-72.

16. Wolff AC, Hammond ME, Hicks DG, Dowsett M, McShane LM, Allison KH, Allred DC, Bartlett JM, Bilous M, Fitzgibbons P, et al. Recommendations for human epidermal growth factor receptor 2 testing in breast cancer: American Society of Clinical Oncology/College of American Pathologists clinical practice guideline update. J Clin Oncol. 2013;31:3997-4013.

17. Wolff AC, Hammond ME, Hicks DG, Dowsett M, MCShane LM, Allison KH, Allred DC, Bartlett JM, Bilous M, Fitzgibbons P, et al. Recommendations for human epidermal growth factor receptor 2 testing in breast cancer: American Society of Clinical Oncology/College of American Pathologists clinical practice guideline update. Arch Pathol Lab Med. 2014;138:241-56.

18. Goldhirsch A, Wood WC, Coates AS, Gelber RD, Thurlimann B, Senn $\mathrm{HJ}$, Panel $\mathrm{m}$. Strategies for subtypes - dealing with the diversity of breast cancer: highlights of the St. Gallen International Expert Consensus on the Primary Therapy of Early Breast Cancer 2011. Ann Oncol. 2011:22:1736-47.

19. Mauri D, Pavlidis N, loannidis JP. Neoadjuvant versus adjuvant systemic treatment in breast cancer: a meta-analysis. J Natl Cancer Inst. 2005:97:188-94. 
20. Mieog JS, van der Hage JA, van de Velde CJ. Preoperative chemotherapy for women with operable breast cancer. Cochrane Database Syst Rev. 2007:(2):CD005002.

21. Buzdar AU, Valero V, Ibrahim NK, Francis D, Broglio KR, Theriault RL, Pusztai L, Green MC, Singletary SE, Hunt KK, et al. Neoadjuvant therapy with paclitaxel followed by 5 -fluorouracil, epirubicin, and cyclophosphamide chemotherapy and concurrent trastuzumab in human epidermal growth factor receptor 2-positive operable breast cancer: an update of the initial randomized study population and data of additional patients treated with the same regimen. Clin Cancer Res. 2007;13:228-33.

22. Eisenhauer EA, Therasse P, Bogaerts J, Schwartz LH, Sargent D, Ford R, Dancey J, Arbuck S, Gwyther S, Mooney M, et al. New response evaluation criteria in solid tumours: revised RECIST guideline (version 1.1). Eur J Cancer. 2009:45:228-47.

23. McShane LM, Altman DG, Sauerbrei W, Taube SE, Gion M, Clark GM. Statistics subcommittee of the NCIEWGoCD: REporting recommendations for tumor MARKer prognostic studies (REMARK). Nat Clin Pract Urol. 2005;2:416-22.

24. Adams S, Gray RJ, Demaria S, Goldstein L, Perez EA, Shulman LN, Martino S, Wang M, Jones VE, Saphner TJ, et al. Prognostic value of tumor-infiltrating lymphocytes in triple-negative breast cancers from two phase III randomized adjuvant breast cancer trials: ECOG 2197 and ECOG 1199. J Clin Oncol. 2014;32:2959-66.

25. Denkert C, von Minckwitz G, Brase JC, Sinn BV, Gade S, Kronenwett R, Pfitzner BM, Salat C, Loi S, Schmitt WD, et al. Tumor-infiltrating lymphocytes and response to neoadjuvant chemotherapy with or without carboplatin in human epidermal growth factor receptor 2-positive and triple-negative primary breast cancers. J Clin Oncol. 2015;33:983-91.

26. Loi S, Sirtaine N, Piette F, Salgado R, Viale G, Van Eenoo F, Rouas G, Francis $P$, Crown JP, Hitre E, et al. Prognostic and predictive value of tumorinfiltrating lymphocytes in a phase III randomized adjuvant breast cancer trial in node-positive breast cancer comparing the addition of docetaxel to doxorubicin with doxorubicin-based chemotherapy: BIG 02-98. J Clin Oncol. 2013;31:860-7.

27. Loi S, Michiels S, Salgado R, Sirtaine N, Jose V, Fumagalli D, KellokumpuLehtinen PL, Bono P, Kataja V, Desmedt C, et al. Tumor infiltrating lymphocytes are prognostic in triple negative breast cancer and predictive for trastuzumab benefit in early breast cancer: results from the FinHER trial. Ann Oncol. 2014;25:1544-50.

28. Dai X, Li T, Bai Z, Yang Y, Liu X, Zhan J, Shi B. Breast cancer intrinsic subtype classification, clinical use and future trends. Am J Cancer Res. 2015;5:2929-43.

29. Orzechowska M, Jedroszka D, Bednarek AK. Common profiles of Notch signaling differentiate disease-free survival in luminal type $A$ and triple negative breast cancer. Oncotarget. 2017;8:6013-32.

30. Hortobagyi GN. Treatment of breast cancer. N Engl J Med. 1998;339:974-84.

31. Ogiya A, Yamazaki K, Horii R, Shien T, Horimoto Y, Masuda N, Inao T, Hosoda M, Ishida N, Osako T, et al. Post-relapse survival in patients with the early and late distant recurrence in estrogen receptor-positive HER2negative breast cancer. Breast Cancer. 2017;24:473-82.

32. van de Ven S, Smit VT, Dekker TJ, Nortier JW, Kroep JR. Discordances in ER, PR and HER2 receptors after neoadjuvant chemotherapy in breast cancer. Cancer Treat Rev. 2011;37:422-30.

33. Guarneri V, Dieci MV, Barbieri E, Piacentini F, Omarini C, Ficarra G, Bettelli S, Conte PF. Loss of HER2 positivity and prognosis after neoadjuvant therapy in HER2-positive breast cancer patients. Ann Oncol. 2013;24:2990-4.

34. Hayashi N, Nakamura S, Tokuda Y, Shimoda Y, Yagata H, Yoshida A, Ota H, Hortobagyi GN, Cristofanilli M, Ueno NT. Prognostic value of HER2-positive circulating tumor cells in patients with metastatic breast cancer. Int J Clin Oncol. 2012;17:96-104.

35. Hench IB, Hench J, Tolnay M. Liquid biopsy in clinical management of breast, lung, and colorectal cancer. Front Med. 2018;5:9.
Ready to submit your research? Choose BMC and benefit from:

- fast, convenient online submission

- thorough peer review by experienced researchers in your field

- rapid publication on acceptance

- support for research data, including large and complex data types

- gold Open Access which fosters wider collaboration and increased citations

- maximum visibility for your research: over $100 \mathrm{M}$ website views per year

At BMC, research is always in progress.

Learn more biomedcentral.com/submissions 